\title{
Molecular Determinants Required for the Avirulence Function of AvrPphB in Bean and Other Plants
}

\author{
Anastasia P. Tampakaki, ${ }^{1}$ Marina Bastaki, ${ }^{1,3}$ John W. Mansfield, ${ }^{2}$ and Nickolas J. Panopoulos ${ }^{1,3}$ \\ ${ }^{1}$ Institute of Molecular Biology and Biotechnology, Foundation for Research and Technology-Hellas, Vassilika Vouton, P. O. \\ Box 1527, 71110 Heraklion, Crete, Greece; ${ }^{2}$ Department of Agricultural Sciences, Imperial College, Wye, Ashford, Kent, \\ TN25 5AH, UK; ${ }^{3}$ Department of Biology, University of Crete, P.O. Box 2208 Vassilika Vouton 71110, Heraklion, Crete, \\ Greece
}

Submitted 2 July 2001. Accepted 30 November 2001.

\begin{abstract}
The avirulence gene avrPphB from Pseudomonas syringae pv. phaseolicola determines incompatibility, manifested as a hypersensitive reaction (HR), on bean cultivars carrying the $R 3$ resistance gene and also confers avirulence on other plants. The AvrPphB protein carries an embedded consensus myristoylation motif and is cleaved in bacteria and certain plants to yield fragments of about 6 and $28 \mathrm{kDa}$. We investigated plant recognition and type III translocation determinants in AvrPphB by constructing three N-terminally truncated and two site-directed mutants carrying substitutions in the conserved G63 residue of the myristoylation motif, which lies adjacent to the proteolytic cleavage site. The peptides were either delivered to plant cells by pseudomonads or were expressed transiently in planta via the Agrobacterium tumefaciens or Potato virus $X$. The 63 amino terminal residues were required for type III-mediated translocation from Pseudomonas strains to the plant, but were partially dispensable for effector recognition following in planta expression. Substitution of the G63 residue resulted in differential HR phenotypes in two different $R 3$ cultivars of bean and abolished effector processing in Pseudomonas strains. Agrobacterium-mediated expression of the mutant proteins elicited $H R$ in resistant bean hosts and in tomato but elicited no reaction in Nicotiana species.
\end{abstract}

Additional keywords: pathogenicity, receptor, signaling, type III secretion.

Race- and cultivar-specific resistance to halo-blight in bean (Phaseolus vulgaris L.) is based on gene-for-gene interactions involving five genes for resistance $(R)$ in the host and five matching genes for avirulence (avr) in the pathogen, Pseudomonas syringae pv. phaseolicola (Jenner et al. 1991; Mansfield et al. 1994). Three $a v r$ genes from this pathogen, those matching $R 1, R 2$, and $R 3$, have been cloned and sequenced (Jenner et al. 1991; Mansfield et al. 1994; Tsiamis et al. 2000). One of these, avrPphB, matches $R 3$ from Phaseolus vulgaris. Identical alleles of $a v r P p h B$ occur in races 3 and 4 of $P$. syringae pv. phaseolicola, which cause a characteristically rapid hypersensitive reaction (HR) in bean cultivars with $R 3$ (Jenner et al. 1991; Mansfield et al. 1994). No DNA sequences hybridizing to probes for $a v r P p h B$ are found in strains of $P$. syringae pv. phaseolicola that are virulent on $R 3$ cultivars, indicating that $a v r P p h B$ is not generally required for pathogenicity in the

Corresponding author: N. J. Panopoulos: University of Crete; Telephone: +30-81-394369; Fax: +30-81-394408; E-mail: panopoul@ imbb.forth.gr halo-blight bacterium. avrPphB also confers avirulence to pea, soybean, and Arabidopsis after transfer to appropriate bacterial pathogens that are virulent on these hosts (Fillingham et al. 1992; Pirhonen et al. 1996; Simonich and Innes 1995). In Arabidopsis, the matching $R$ gene, RPS5, has been cloned (Simonich and Innes 1995; Warren et al. 1999). Determination of specificity in such a wide range of plants has now been reported for other bacterial $a v r$ genes from other pathovars of $P$. syringae, notably avrB, avrRpml, and its homologue avrPphA1.R2 (Dangl et al. 1992; Fillingham et al. 1992; Grant et al. 1995; Vivian et al. 1997).

Accumulating evidence suggests that bacterial avirulence (Avr) proteins are delivered inside the host cells through the hrp/hrc-encoded type III secretion system (TTSS) and are subsequently recognized either directly or indirectly by the corresponding $R$ gene products. This hypothesis is based primarily on studies showing that several Avr proteins elicit resistance gene-dependent cell death when they are expressed in planta (Galan and Collmer 1999; Gopalan et al. 1996; Leister et al. 1996; Van den Ackerveken and Bonas 1997). However, the physical transfer of Avr proteins has not been demonstrated directly. In most cases, the final destination of Avr proteins following delivery to the plant cell is not clear, exceptions being the AvrBs3 family members of Xanthomonas, which evidently are targeted to the plant nucleus via eukaryotic nuclear localization signals (Van den Ackerveken et al. 1996; Yang and Gabriel 1995; Zhu et al. 1998, 1999).

A subset of $P$. syringae type III effectors, AvrB, AvrC, AvrRpm1, AvrPto, and AvrPphB, contain potential myristoylation motifs at their amino termini. Protein N-myristoylation is responsible for the localization of many eukaryotic proteins to the plasma membrane or to the other intracellular membranes (Resh 1994, 1999; Towler et al. 1988). Although N-myristoylation has only been observed in eukaryotes, myristoylation and other types of acylation of Avr effectors occur inside plant cells and mediate their proper localization to the plant plasma membrane, where molecular recognition events presumably take place (Nimchuk et al. 2000; Shan et al. 2000). AvrPphB is unusual among this group of effectors in two respects. First, its consensus N-myristoylation site is embedded in the sequence $\left(\mathrm{G}_{63} \mathrm{CASSGVS}_{70}\right)$ rather than being amino-terminal, and substitution of glycine at position 63 to an alanine abolishes membrane association and avirulence function in Arabidopsis Col-0 plants, which possess the matching RPS5 gene (Nimchuk et al. 2000). Second, the protein is cleaved in Escherichia coli between residues K62 and G63, yielding a $28 \mathrm{kDa}$ and a $6 \mathrm{kDa}$ species (Puri et al. 1997). Similar processing of AvrPphB occurred in P. syringae pv. phaseolicola, as well as in Arabi- 
dopsis, when the protein was expressed endogenously. The exact site and the role of processing in Type III-mediated translocation or in planta recognition have not yet been elucidated. However, Nimchuk and associates (2000) proposed that cleavage potentially exposes the G63 residue within the putative myristoylation motif, enabling subsequent modification of the $28-\mathrm{kDa}$ species and membrane association of the truncated protein. It is interesting that the myristoylation motif borders with the proteolytic cleavage site determined in E. coli. However, it has not been determined whether the processing of AvrPphB affects $\mathrm{R}$ receptor recognition or translocation via the bacterial type III apparatus.

The processing of AvrPphB is of further interest in light of current knowledge concerning the translocation of effector proteins via the type III secretion apparatus. Type III effectors lack a classical signal peptide and other common sequence features. However, recent studies showed that the TTSS machinery recognizes effector proteins by two signals in their amino termini: a secretion signal and a translocation signal (Sory et al. 1995). Secretion signals have been mapped in several Yop proteins to sequences encoding the amino-terminal 15-amino acid residues (Cornelis 2000; Cornelis and Van Gijsegem 2000) or their codons (Anderson and Schneewind 1997; Anderson et al. 1999). Translocation signals are located within the amino-terminal 50- to 100-amino acid residues of several Yop effectors
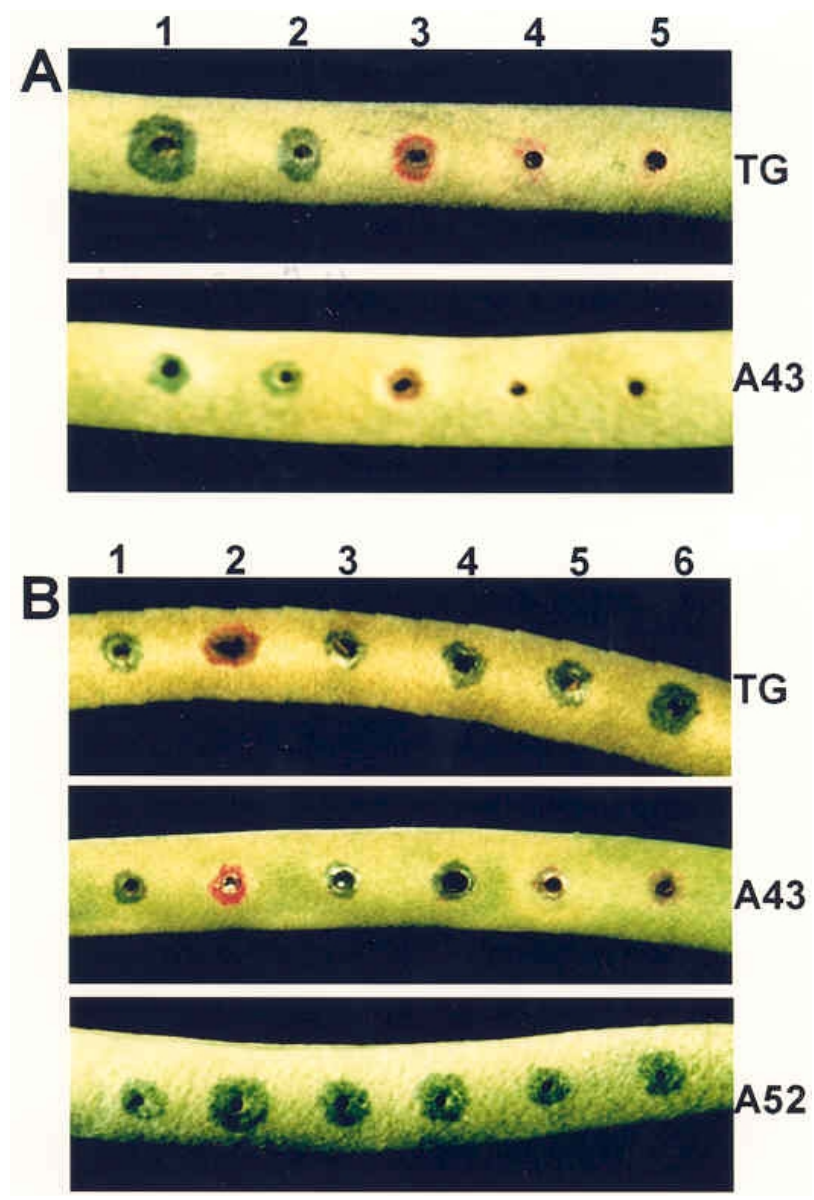

Fig. 1. A, Reaction phenotypes in pods of cultivars Tendergreen (TG) and A43 3 days after inoculation with (1) R6, (2) R6 containing the vector, (3) R6 expressing $a v r P p h B$, (4) R6 $6 h r p A$, and (5) R6 $6 h r p A$ expressing $a v r P p h B$. B, Reaction phenotypes in pods of cvs. TG, A43, and A52 3 days after inoculation with (1) Race 6 containing the vector, (2) expressing $a v r P p h B$, (3) N $\Delta 63$, (4) N $\Delta 109$, (5) G63A, and (6) G63E. Cvs. TG and A43 are resistant to Pseudomonas syringae pv. phaseolicola $($ avrPphB $)$ strains, cv. A52 is susceptible.
(Plano et al. 2001), which are required for binding to their cognate chaperone. Although most Avr proteins are not secreted extracellularly by bacteria grown under $h r p$-inducing conditions, a subset of Avr proteins can be secreted to some degree under certain conditions by strains expressing either homologous or heterologous type III-secretion systems (Ham et al. 1998; Van Dijk et al. 1999). Recently, it was suggested that the first 15 codons of avrPto and the first 18 codons of AvrBs2 might carry a potential m-RNA targeting signal (Anderson et al. 1999; Mudgett et al. 2000).

To define the sequence features of AvrPphB that are required for translocation via the TTSS to the host cells and for effectorhost cell recognition, we carried out deletion and site-directed mutagenesis studies. Transient expression of both the fulllength AvrPphB protein and the $28-\mathrm{kDa}$ species lacking the 63 $\mathrm{N}$-terminal residues inside plant cells in bean cultivars, as well as in several nonhost plant species, was achieved by agroinfiltration and Potato virus $X$ (PVX) infection, respectively. Our results clearly show that deletion of the $63 \mathrm{~N}$-terminal amino acids only partially reduced elicitor activity after in planta expression but completely abolished avirulence function in $P$. syringae pv. phaseolicola. Our results clearly show that the 63 $\mathrm{N}$-terminal amino acids are required for full elicitor activity as well as for type III translocation. Site-directed mutagenesis further showed that processing of AvrPphB appears to be important for translocation in a host-dependent manner and that the putative myristoylation motif is differentially required for elicitation of the HR in different plant species.

\section{RESULTS}

\section{The bacterial TTSS is required for the expression of AvrPphB-dependent avirulence.}

To determine whether the type III-secretion apparatus of $P$. syringae pv. phaseolicola is involved in AvrPphB delivery to the plant, we introduced a broad-host range plasmid expressing the AvrPphB protein under the lac promoter into a wild-type Race 6 strain ( $P$. syringae pv. phaseolicola R6) and in a TTSSdeficient mutant that carries a nonpolar deletion in the structural gene for the Hrp pilus subunit (R6 $\Delta h r p A)$. P. syringae pv. phaseolicola R6 is virulent on all bean cultivars used in this study, as previously reported (Taylor et al. 1996). The R6 $\Delta h r p A$ mutant was neither pathogenic nor did it elicit HR in bean, regardless of the presence or absence of the $R 3$ gene (Lee et al. 2001). The $P$. syringae pv. phaseolicola $\mathrm{R} 6$ transconjugants expressing $a v r P p h B$ (R6-avrPphB) caused brown necrosis, a manifestation of HR, in leaves as well as in pods of bean cultivars in an $R 3$-dependent manner, while the pilus-deficient transconjugants (R6 $\Delta$ rpA-avrPphB) caused neither watersoaking nor HR (Fig. 1A). Western blot analysis of total cell extracts with a polyclonal AvrPphB antibody showed that the protein was expressed and processed normally in the $P$. syringae pv. phaseolicola bacteria, indicating that constitutive expression of AvrPphB or the $\Delta h r p A$ mutation does not interfere with the processing of the protein in $P$. syringae pv. phaseolicola (data not shown). The results clearly show that a functional hrp-encoded TTSS is required for AvrPphB delivery from the bacteria to the plant.

\section{The $63 \mathrm{~N}$-terminal residues are partially dispensable for the avirulence function of AvrPphB.}

We were interested in defining the role of AvrPphB processing in the bacterial host and in defining the structural requirements for delivery and host recognition of the effector. Initially, deletion mutants of $a v r P p h B$ were constructed by introducing an ATG codon before codons 64 and 110, simultaneously removing the corresponding $\mathrm{N}$-terminal regions (mutant 
designations $\mathrm{N} \Delta 63$ and $\mathrm{N} \Delta 109$, respectively). The mutants were cloned in a broad-host range vector and were introduced in $P$. syringae pv. phaseolicola R6. Next, transconjugants expressing the wild-type AvrPphB protein (R6-avrPphB), the two deletion mutants (R6-N $\Delta 63$ and R6-N $\Delta 109$ ), or the empty vector (R6-EV) were used to inoculate pods of resistant and susceptible bean cultivars, and the symptoms were scored 3 days after inoculation. As expected, R6-EV transconjugants developed typical water-soaked lesions in pods of bean cultivars possessing or lacking the $R 3$ gene. The R6- $a v r P p h B$ transconjugants caused brown necrotic lesions that are characteristics of the HR in pods of cvs. Tendergreen (TG) and A43, which carry the $R 3$ gene. In contrast, R6-N $\Delta 63$ and R6-N $\Delta 109$ transconjugants developed water-soaked lesions on pods of these cultivars (Table 1, Fig. 1B). To rule out the possibility that the loss of avirulence activity in these mutants is a result of reduced stability and abundance of the protein, total cell extracts, as well as the culture mediums of R6- $\operatorname{vrPphB}, \mathrm{R} 6-\mathrm{N} \Delta 63$, and R6-N $\Delta 109$ transconjugants grown on hrp-inducing medium, were examined by Western blot analysis using the polyclonal AvrPphB-specific antibody. Both mutant polypeptides accumulated normally in P. syringae pv. phaseolicola R6, as did the full-length protein, but neither these, nor the full-length AvrPphB or its $28-\mathrm{kD}$ form could be detected in the culture medium (data not shown). These results suggest that the $63 \mathrm{~N}$ terminal amino acids of AvrPphB are necessary either for its translocation through the TTSS or for recognition by the cognate plant receptor.

\section{In planta recognition determinants of AvrPphB.}

To investigate whether the $63 \mathrm{~N}$-terminal residues of AvrPphB were required for effector recognition, deletion mutants N $\Delta 63$ and N $\Delta 109$ were transferred to a binary Agrobacterium vector and were tested for their ability to cause HR in different plant species by agroinfiltration. The $\mathrm{N} \Delta 63$ mutant, but not $\mathrm{N} \Delta 109$, triggered weaker and delayed necrosis in comparison with the full-length protein in bean cultivars carrying the $R 3$ gene (Table 1, Fig. 2A). Neither the mutants nor the wildtype protein elicited HR on bean cultivars lacking the $R 3$ gene, indicating that the necrosis caused by the wild type and the $\mathrm{N} \Delta 63$ effector is $R 3$ gene specific. Similar weak HR activity was observed on three other nonhost plant species, namely, tomato (cvs. Rio Grande 76S and 76R), tobacco (cvs. Xanthi and W38), and Nicotiana benthamiana (Table 1, Fig. 2B). The presence of $R 3$ gene homologues in $N$. benthamiana was also investigated by introducing the broad-host range plasmid ex- pressing the wild-type $a v r P p h B$ and the compatible cosmid pPL6, which carries the entire hrp cluster from $P$. syringae pv. phaseolicola strain NPS3121 (Lindgren et al. 1986) into the nonpathogenic bacterium $P$. fluorescens. Transconjugants carrying both plasmids elicited $\mathrm{HR}$, while those carrying the cosmid or the plasmid expressing $a v r P p h B$ alone did not elicit any reaction (data not shown). Thus, $N$. benthamiana evidently carries a matching resistance gene for $a v r P p h B$.

Conceivably, the weaker HR phenotype of the N $\Delta 63$ mutant may be due to decreased stability or lower accumulation of the truncated proteins in the plant, or both, or to the removal of molecular determinants involved in recognition by the cognate $\mathrm{R}$ receptor. However, we were not able to detect AvrPphB or the mutant proteins in agroinfiltrated leaves of tomato, bean, and tobacco by Western blot analysis, which suggests that all forms of the effector are rapidly degraded in planta, as previously reported for AvrPphB and other Avr effectors in Arabidopsis (Nimchuk et al. 2000).

To compensate for possible reduced accumulation of the $\mathrm{N} \Delta 63$ protein in the agroinfiltrated leaves, we sought to increase its accumulation level by expressing the truncated $\mathrm{N} \Delta 63$ gene from a PVX vector, which in our previous work (Tampakaki and Panopoulos 2000) gave substantially greater quantities of another HR elicitor, $\mathrm{HrpZ}_{\mathrm{Psph}}$, in planta. As PVX cannot infect bean, we used $N$. benthamiana and tomato as resistant plant hosts. Plants inoculated with the empty PVX vector developed chlorotic mosaic, the typical symptoms of PVX infection, in the upper noninoculated leaves 1 week after inoculation. In contrast, plants infected with the recombinant virus PVX202::avrPphB developed necrotic lesions in the upper noninoculated leaves within 5 to 7 days (Fig. 2C), whereas the $\mathrm{N} \Delta 63$ mutant caused delayed necrosis in both plant species (Table 1). However, as with agroinfiltrated leaves, we could detect neither the wild-type nor the mutant protein in PVX-inoculated leaves.

It is possible that protein instability in planta may have been responsible for the weaker $\mathrm{HR}$ elicitor activity of $\mathrm{N} \Delta 63$, but another possible explanation may be the absence of the G63 residue (Fig. 3). Nimchuk and associates (2000) hypothesized that the full-length protein $(35 \mathrm{kDa})$ is cleaved in planta to produce an HR-active $28-\mathrm{kDa}$ species and that this cleavage exposes the G63 residue for possible myristoylation. To investigate the possibility that the G63 residue was essential for the HR-elicitor activity of the 28-kDa form of AvrPphB, we used another deletion mutant, $\mathrm{N} \Delta 62$, in which an ATG codon had been introduced just before the G63 codon (Stevens et al.

Table 1. Hypersensitive reaction (HR) phenotypes in bean and other plants ${ }^{\mathrm{a}}$

\begin{tabular}{|c|c|c|c|c|c|c|c|c|}
\hline Plant and cultivar ${ }^{b}$ & $R 3$ gene allele & Delivery vehicle $^{c}$ & $\operatorname{AvrPphB}^{\mathrm{d}}$ & $\mathbf{N} \Delta 62$ & $\mathbf{N} \Delta 63$ & $\mathbf{N} \Delta \mathbf{1 0 9}$ & G63A & G63E \\
\hline \multirow[t]{2}{*}{ Bean cv. Tendergreen (TG) } & + & Agro & $+++^{\circ}$ & ++ & ++ & - & +++ & +++ \\
\hline & & Psph & +++ & - & - & - & & \\
\hline \multirow[t]{2}{*}{ Bean cv. A43 } & + & Agro & +++ & ++ & ++ & - & +++ & \\
\hline & & Psph & +++ & - & - & - & $++(+)^{\mathrm{f}}$ & $++(+)$ \\
\hline \multirow{2}{*}{ Bean cv. A52 } & - & Agro & - & - & - & - & - & - \\
\hline & & Psph & - & - & - & - & - & - \\
\hline \multirow{2}{*}{ Bean cv. Canadian Wonder (CW) } & - & Agro & - & - & - & - & - & - \\
\hline & & Psph & - & - & - & - & - & - \\
\hline Tomato & Unknown & Agro & +++ & ++ & ++ & - & +++ & +++ \\
\hline N. benthamiana & Unknown & Agro & +++ & ++ & ++ & - & - & - \\
\hline Tobacco & Unknown & Agro & +++ & ++ & ++ & - & - & - \\
\hline
\end{tabular}

${ }^{a}$ Induced by AvrPphB deletion and site-directed mutant polypeptides delivered by Pseudomonas syringae pv. phaseolicola or Agrobacterium-mediated transient assay.

${ }^{\mathrm{b}}$ Known genes for resistance to $P$. syringae pv. phaseolicola in bean cultivars are as follows: TG, R3; A43, R2, R3 R4, R5; A52, R4; CW, none.

${ }^{\mathrm{c}}$ Agro $=$ Agrobacterium-mediated transient expression of corresponding gene; Psph $=$ P. syringae pv. phaseolicola Race 6 harboring avrPphB allele in pBBR1MCS2 broad-host range vector.

d AvrPphB = wild-type protein, deletion or site directed mutants described in text,

e Severity of HR was scored relative to rapid reaction. $+++=$ full $\mathrm{HR} ;-=$ no response; $++=$ intermediate reaction between - and +++ .

${ }^{\mathrm{f}}$ Reaction was scored as +++ in cv. A43 leaves and ++ in pods. 
1998). However, this mutant had an identical phenotype to $\mathrm{N} \Delta 63$ in agroinfiltration tests on all resistant bean cultivars and in the nonhost species that were tested (Table 1). Although myristoylation of AvrPphB has not been demonstrated biochemically, it is tempting to speculate that an intact myristoylation motif may not be required for HR elicitation by AvrPphB or its truncated effectors in some plant hosts. An alternative scenario is that removal of the initiator methionine, a prerequisite for posttranslational myristoylation (Resh 1994), does not take place with the $\mathrm{N} \Delta 62$ effector, as proposed for other Avr proteins (AvrB and AvrRpm1) that have an N-terminal myristoylation motif with the conserved glycine residue next to the initiator methionine. Regardless of which of these or other possible explanations is correct, our results suggest that the entire AvrPphB protein is required for full HR elicitation.

\section{Differential phenotypes of site-directed AvrPphB mutants in resistant bean hosts and nonhost plants.}

Since the G63 residue is part of both the putative myristoylation motif and the proteolytic cleavage site, we examined whether substitution of this residue affected host recognition of the protein or affected the processing or translocation, or both, in Pseudomonas strains by constructing two site-directed mutants. In one mutant, G63A, the glycine residue at position 63 was changed to alanine, a commonly used replacement that abolishes myristoylation (Resh 1999). In the other mutant, G63EC64F, the same residue was changed to glutamic acid and the cysteine at position 64 to phenylalanine, which is also excluded from the consensus myristoylation motif (Fig. 3). This mutant will be referred to hereafter as G63E for brevity.
We expressed these mutants in bean, tomato, tobacco, and $N$. benthamiana by the Agrobacterium transient expression assay. Surprisingly, both mutants induced cell death in the bean cvs. TG and A43, which carry the matching $R 3$ resistance gene, as well as in tomato (Table 1, Fig. 2A and B). The observed cell death was phenotypically indistinguishable from that caused by wild-type protein. In contrast, no significant necrosis was observed in bean cvs. Canadian Wonder and A52, which lack the $R 3$ gene, in tobacco, or in $N$. benthamiana (Table 1). These results suggest that the presence of the G63 residue is dispensable for full $\mathrm{HR}$ elicitor activity of AvrPphB in $R 3$ bean cultivars and in tomato but is essential in tobacco and $N$. benthamiana, indicating that processing or myristoylation, or both, play an important role in Nicotiana species.

Because the G63A and G63E mutants were fully HR active in $R 3$ bean cultivars when they were expressed via Agrobacterium tumefaciens, we examined whether they conferred avirulence to the virulent strain $P$. syringae pv. phaseolicola R6. Surprisingly, transconjugants expressing the mutant proteins did not elicit HR in pods or leaves of cv. TG (Table 1, Fig. 1) and developed water-soaked lesions, as did the virulent R6-EV transconjugants. One possible explanation is that the mutant proteins are either unstable in Pseudomonas strains, or they are not translocated via the type-III pathway. Next, we examined whether these proteins were stable and processed normally in R6-G63A and R6-G63E transconjugants. Western blot analysis showed both G63A and G63E accumulated to the same level as AvrPphB in the transconjugants but, unlike the wild-type protein, were not processed (Fig. 4). These results indicate that processing may be an essential step in type III-mediated deliv-
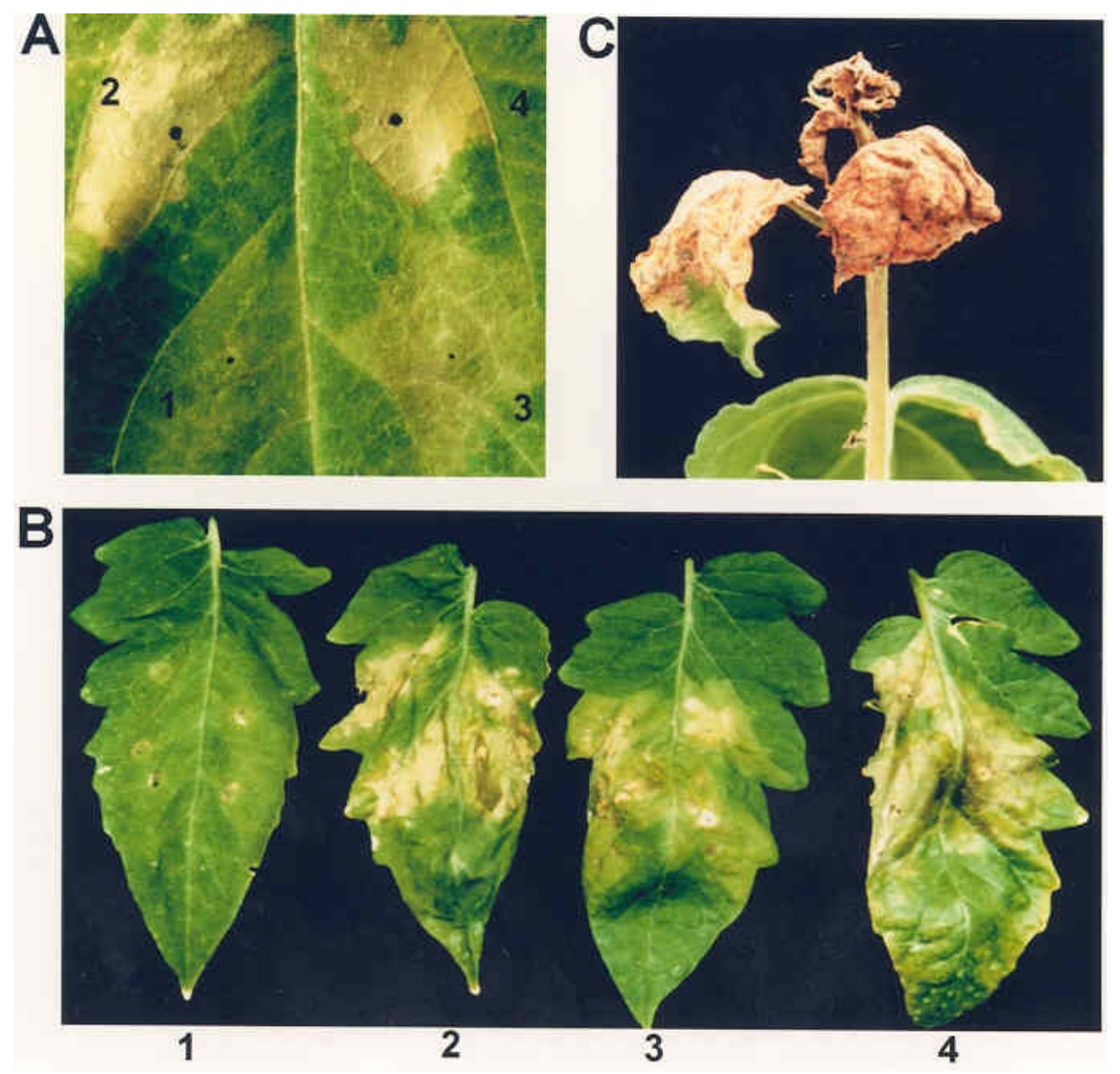

Fig. 2. A, Agrobacterium-mediated transient expression of $\operatorname{avpphB}$ in resistant bean cultivar Tendergreen. Leaves were inoculated with suspension of Agrobacterium tumefaciens strain C58C1 carrying (1) vector pBin-Hyg-Tx, (2) pBin/avrPphB, (3) pBin/N $\Delta 63$, and (4) pBin/G63A. The leaf was photographed 3 days after inoculation. B, Agrobacterium-mediated transient expression of avrPphB in tomato cv. Rio Grande 76S. Leaves were inoculated as in A, and were photographed 3 days after inoculation. C, Necrotic phenotype of Nicotiana benthamiana inoculated with PVX::avrPphB, photographed 7 days after inoculation. Both species are nonhosts (i. e., resistant) to Pseudomonas syringae pv. phaseolicola. 
ery. However, after inoculation of R6-G63A and R6-G63E transconjugants, cv. A43 developed a weak HR in pods (Fig. 1) and a reaction in leaves that was almost as rapid as that observed to wild-type AvrPphB. Taken together, the above results clearly indicate that the mutant proteins are potentially capable of translocation from bacteria to the plant; however, their delivery to the plant seems to be host dependent.

\section{DISCUSSION}

We have characterized the molecular signals of AvrPphB required for receptor recognition in various plant species and for type III-mediated delivery from $P$. syringae pv. phaseolicola to bean plants. We provide evidence that the $\mathrm{N}$-terminal domain carries determinants whose alteration prevents effector processing in the bacterium, impairs its delivery to the plant cells via the bacterial TTSS in a plant-dependent manner, and results in differential HR phenotypes on different hosts. In particular, we show that the region defined by amino acid residue G63, which overlaps the putative myristoylation motif and borders the proteolytic cleavage site, is essential for HR-eliciting activity in $N$. benthamiana and tobacco plants but is dispensable in bean and tomato, suggesting that recognition specificity between AvrPphB and the $R$ gene products is plant genotype dependent.

$P$. syringae pv. phaseolicola R6 expressing $a v r P p h B$ was capable of delivering the AvrPphB signal to bean plants, and this process required a functional TTSS. Deletion of $h r p A$, the gene coding for the Hrp pilus structural protein, in P. syringae pv. phaseolicola R6 prevented the induction of $\mathrm{HR}$ in resistant bean cultivars. Furthermore, P. syringae pv. phaseolicola R6 transconjugants expressing $\mathrm{N}$-terminal deletion mutants of AvrPphB did not cause HR in pods or leaves of the resistant bean cvs. TG and A43 carrying the matching $R 3$ gene. This was attributed primarily to a defect in translocation via the TTSS rather than to lack of effector recognition by the host, because the $\mathrm{N} \Delta 63$ mutant effector triggered $R 3$ gene-specific necrosis in bean cultivars, although weaker than the wild-type effector, when the truncated genes were introduced into the plants through agroinfiltration.

The weaker HR phenotype of $\mathrm{N} \Delta 63$ in agroinfiltrated bean leaves suggested that the $\mathrm{N}$-terminal 63 residues of AvrPphB may carry some host-recognition determinants. An alternative explanation is that the truncated effector was less stable and accumulated to lower levels in bean. This possibility was investigated further by expressing the full-length and the truncated protein in three nonhost plants, namely tobacco, $N$. benthamiana, and tomato, by means of agroinfiltration and, in the latter two species, by PVX infection as well. In the agroinfiltration assay, this mutant gave weaker necrosis on all three nonhost species, similar to the results obtained in bean. In the PVX assay, the full-length AvrPphB effector gave progressive necrosis of the entire plant in $N$. benthamiana and in tomato, while the $\mathrm{N} \Delta 63$ mutant caused similar necrosis in both species but with significant delay in comparison to the full-length protein. We could detect neither the full-length nor the mutant proteins ( $\mathrm{N} \Delta 62, \mathrm{~N} \Delta 63$, and $\mathrm{N} \Delta 109$ ) in agroinfiltrated leaves or in PVX infected plants (only WT and N $\Delta 63$ were tested in this system) by Western blot analysis. Although the possibility that the weaker phenotype of the deletion mutants was a result of insufficient effector accumulation remains open, we consider it unlikely, at least in the case of PVX-mediated delivery of $\mathrm{N} \Delta 63$, since this system gives very high levels of protein accumulation (Tampakaki and Panopoulos 2000).

Nimchuk and associates (2000) reported that disruption of the putative myristoylation motif of AvrPphB by a G63A substitution reduced the HR-eliciting activity and membrane localization in Arabidopsis. Although myristoylation of this effector remains to be demonstrated biochemically, we hypothesized that the truncated $\mathrm{N} \Delta 63$ effector may not be properly localized in planta, due to the absence of the G63 residue (presumed myristoyl group acceptor) and the consequent lack of myristoylation. This possibility was ruled out by the finding in the agroinfiltration assay that the $\mathrm{N} \Delta 62$ mutant in which this residue was present next to an initiator methionine, a proper context for myristoylation (Resh et al. 1999), gave an identical phenotype to $\mathrm{N} \Delta 63$. Taken together, the phenotypes observed with the deletion mutants indicate that the first 63 residues of AvrPphB are partially dispensable, while residues 64 to 109 are indispensable for effector recognition in $R 3$ of bean, tomato, tobacco, and $N$. benthamiana.

In planta expression of the two site-directed mutants, G63A and G63E, by the agroinfiltration assay revealed different phenotypes, depending on the host. Both mutants exhibited the same necrotic phenotype as the wild-type protein in resistant bean cultivars as well as in tomato, but neither of them elicited any necrosis in $N$. benthamiana or tobacco. These results were surprising and raised several interesting questions. First, what is the molecular and cellular basis of the differential reactions of these mutants in $N$. benthamiana and tobacco in comparison with the wild-type protein? Second, if myristoylation of AvrPphB occurs following proteolytic cleavage next to G63 and subsequent removal of the initiator methionine as hypothesized by Nimchuk and associates (2000), what functionally differentiates the G63A mutant from N $\Delta 62$ ? Clearly, the G63 residue is crucial for the HR elicitor activity of the full-length effector in the two Nicotiana species but makes no difference in bean and tomato and is immaterial in the case of the N $\Delta 63$ effector in all four species examined (Table 1). Unfortunately, we were not able to detect the wild-type or the mutant proteins in planta and thus cannot evaluate the relative importance of effector accumulation in planta processing and cellular localization in the differential effector-plant recognition. However, several other plausible scenarios are worthy of mention. First, not all proteins that contain a myristoylation motif are myristoylated in vivo, and some proteins that are myristoylated clearly do not require it for their function (Resh 1994; YingTsu et al. 1998; Zhu et al. 1995). In a further variation of this theme, myristoylation may be important in some hosts but not in others. For example, it is possible that myristoylation of AvrPphB is not necessary in bean and tomato but is crucial in the two Nicotiana species. Second, it is conceivable that the G63A substitution does not alter the effector properties of the protein, including its potential myristoylation, in bean and tomato but does so in the two Nicotiana species (our results) and in Arabidopsis species (Nimchuck et al. 2000). Third, proteolytic processing (of the site-directed mutants) or removal of the initiator methionine (in the case of the $\mathrm{N} \Delta 62$ mutant), both presumed prerequisites for myristoylation (see below), may not take place in the two Nicotiana species. If proteolytic processing occurred in these plants at the same site as in E. coli, we would expect the G63A protein to produce the same phenotype as $\mathrm{N} \Delta 62$. In preliminary experiments, no degradation of ${ }^{35} \mathrm{~S}$-labeled AvrPphB protein was observed after incubation for $2 \mathrm{~h}$ with different plant extracts (data not shown). Finally, it is possible that the corresponding $\mathrm{R}$ receptors have different recognition specificities or that there are fundamental differences in where they localize in the cell and how they function in the different plants. Differential recognition of another Avr protein by cognate plant receptors found in different plants (tomato and tobacco) has been reported for AvrPto, suggesting that multiple $R$ genes might have evolved different recognition specificities for the same Avr protein (Shan et al. 2000).

In addition to the differential phenotypes revealed by the agroinfiltration assay on the nonhost species, the site-directed 
mutant effectors G63A and G63E gave differential HR responses on pods as well as on leaves of different $R 3$ bean cultivars upon delivery by Pseudomonas strains. Thus, both mutants gave typical HR on cv. A43 but not on cv. TG or on cv. Guatemala (data not shown), even though they were fully HRactive on both cultivars in the agroinfiltration assay. Clearly, the proteins are intrinsically capable of being translocated via the bacterial TTSS, since they did confer avirulence on $\mathrm{cv}$. A43. The cultivar-specific differential phenotype of the site-directed mutant effectors could be rationalized in several ways. First, as argued in the case of the differential phenotypes on nonhost species, different bean cultivars may possess different R3-like alleles with slightly different specificities towards AvrPphB. This possibility finds some support in the finding that cv. A43 carries two $R 3$ homologues matching $\operatorname{avrPphB}$ but at different chromosomal locations, while cv. TG carries a single $R 3$ gene locus, as does cv. Guatemala (Teverson 1991). Second, besides differential specificities towards AvrPphB, the two $R 3$ gene homologues in cv. A43 may create a gene-dosage effect that could amplify HR signaling. Third, the receptor homologues in different cultivars may differ from each other in other respects (e. g., myristoylation or other types of acylation) connected with membrane localization. This possibility would be in line with hypotheses advanced by others (Nimchuk et al. 2000; Shan et al. 2000) that membrane-associated receptors might recruit nonmyristoylated effectors to an active complex or vice versa. A fourth possibility is that the host genotype may influence the translocation process itself. For example, cv. A43, but not cvs. TG or Guatemala, might trigger the TTSSmediated effector delivery more efficiently. Such a hypothesis would not be unreasonable given the contact dependence of the TTSS-mediated effector established for other pathogens. Evaluation of these, and perhaps other, hypotheses must wait the cloning of $R 3$ gene homologues from bean and other species and the in vivo demonstration of AvrPphB myristoylation. Furthermore, in planta expression of the mutant effectors under regulated expression systems may enable the detection and quantification of the mutant proteins in planta and help clarify some of the questions raised in the present study.

\section{MATERIAL AND METHODS}

\section{Bacterial strains and media.}

Strains and transconjugants of $P$. syringae pv. phaseolicola and $P$. fluorescens were routinely grown on King's B medium (KB) at $28^{\circ} \mathrm{C}$ (King et al. 1954; Miller 1972). E. coli DH5a and Agrobacterium tumefaciens C58C1 containing the disarmed Ti helper plasmid pGV2260 (Deblaere et al. 1985) were grown using standard techniques (Sambrook et al. 1989). Antibiotics were usually used at the following concentrations

$\begin{array}{lr} & \\ \text { AvrPphB: } & M-(X)_{60}-K^{\downarrow} \text { GCASSSGVSLED ... } \\ \text { N } \triangle 62: & \text { MGCASSSGVSLED... } \\ \text { N } 263: & \text { MCASSSGVSLED... } \\ \text { G63A: } & M-(X)_{60}-\text { KACASSSGVSLED ... } \\ \text { G63E: } & M-(X)_{60}-\text { KEFASSSGVSLED... }\end{array}$

\section{Consensus: G-\{EDRKHPFYW\}-X2-[STAGCN]-\{P\}}

Fig. 3. Comparison of AvrPphB myristoylation motif (in wild-type and mutant polypeptides, underlined) with a consensus myristoylation site derived from various proteins (Boutin 1997; Towler et al. 1988). The arrow indicates the cleavage site of AvrPphB as determined in Escherichia coli (Puri et al. 1997). Mutations in the myristoylation motif are indicated in bold.
( $\mu \mathrm{g} / \mathrm{ml})$ : ampicillin, 100; carbenicillin, 100; kanamycin, 50; rifampicin, 50 .

\section{Plasmid constructions.}

Standard molecular biological procedures were performed as described by Sambrook and associates (1989), unless otherwise stated. The following plasmids were constructed for the present study. The DNA fragment encoding the full-length AvrPphB protein was isolated by polymerase chain reaction (PCR) amplification from a pBR322/avrPphB template and cloned in E. coli expression vector pT7-7 in the broad-host range vector $\mathrm{pBBR} 1 \mathrm{MCS} 2$ (Kovach et al. 1995) for expression in $P$. syringae and in the viral expression vector pPVX202 (Sablowski et al. 1995) and the binary expression vector $\mathrm{pBIN}$ Hyg-Tx (Gatz et al. 1992) for expression in plants. The primers AvrPphB-F and AvrPphB-R (5'-GTTTTGAGGTTCATATGAAAATAGGTAC-3' and 5'-CGGGATCCGGCTGGGTTTTTTGCTTC-3', respectively) were designed to contain restriction sites (NdeI and BamHI, underlined) to facilitate cloning in the corresponding sites of the pT7-7. A 50- $\mu$ l PCR mixture containing $10 \mathrm{pmol}$ of each primer, $100 \mathrm{ng}$ of template DNA, $10 \mathrm{mM} \mathrm{KCl}, 20 \mathrm{mM}$ Tris- $\mathrm{HCl}, \mathrm{pH} 8.8,10 \mathrm{mM}\left(\mathrm{NH}_{4}\right)_{2} \mathrm{SO}_{4}, 2$ $\mathrm{mM} \mathrm{MgSO} 4,0.1 \%$ Triton X-100, $200 \mu \mathrm{M}$ dNTPs, and 2 units of Deep Vent DNA polymerase (New England Biolabs, Inc., Beverly, MA, U.S.A.) was subjected to 25 cycles of amplification $\left(1 \mathrm{~min}\right.$ denaturation at $94^{\circ} \mathrm{C}, 1 \mathrm{~min}$ annealing at $42^{\circ} \mathrm{C}$, and 1 min extension at $72^{\circ} \mathrm{C}$ ). The PCR product was digested with NdeI/BamHI and cloned in corresponding sites of pT7-7. The resulting plasmid construct, pT7-7/avrPphB, was digested with $N d e \mathrm{I} /$ Bam HI and, after filling the ends with Klenow, ligated separately to the NruI of pPVX202 and to the SmaI of pBINHyg-Tx to give PVX202::avrPphB and pBIN/avrPphB, respectively. To construct the pBBR1MCS2/avrPphB plasmid, the coding region of $a v r P p h B$ was obtained by PCR, using as template the pT7-7/avrPphB and the primers T7RBS (5'GTTTAACGGTACCTTTAAGAAGGAGATATACATATG-3') and AvrPhB-R containing a KpnI (underlined) and a BamHI site, respectively. The forward primer, T7RBS, was designed to contain the ribosome binding site (RBS, bold) from pT7-7. The PCR was performed as above, except for the annealing temperature $\left(42^{\circ} \mathrm{C}\right)$. The PCR product was digested with $K p n I$ and BamHI and ligated to corresponding sites of pBBR1MCS2 vector.

To construct a deletion derivative of AvrPphB protein lacking amino acid residues 1 to 62, a PCR fragment encoding the carboxyl-terminal 210 amino acids of AvrPphB was amplified from the pBR322/avrPphB by using the forward primer $\Delta 63-\mathrm{F}$ (5'-CACTGGGCGATCATATGTGTGCATCCTC-3') and the reverse AvrPphB-R primer, simultaneously changing the glycine residue at position 63 to methionine (the ATG codon in the forward primer is italicised, NdeI underlined). The PCR product was digested with $N d e$ I plus BamHI and ligated to corresponding sites of pT7-7. The resulting pT7-7/N $\Delta 63$ plasmid

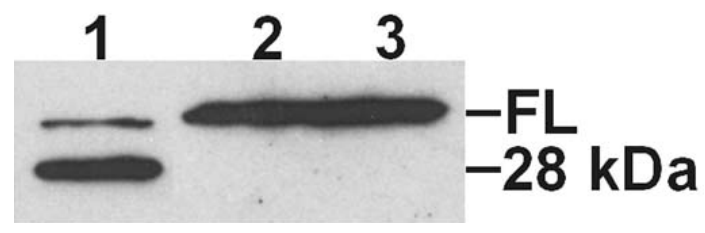

Fig. 4. Immunoblot analysis of AvrPphB in total cellular lysates from Pseudomonas syringae pv. phaseolicola R6 transconjugants grown in rich media. Lane 1, Pseudomonas syringae pv. phaseolicola R6 expressing avrPphB; lane 2, Pseudomonas syringae pv. phaseolicola R6 expressing G63A; and lane 3, Pseudomonas syringae pv. phaseolicola R6 expressing G63E. Both wild-type and mutant genes were constitutively expressed from plasmid pBBR1MCS2. 
was digested with $\mathrm{NdeI}$ and Bam HI and, after filling the ends with Klenow, ligated separately to the NruI site of PVX202 and to the SmaI site of pBIN-Hyg-Tx to give PVX202::N $\Delta 63$ and $\mathrm{pBIN} / \mathrm{N} \Delta 63$ plasmids, respectively. Next, the portion of the coding region of $a v r P p h B$ expressing the carboxyl-terminal 210 amino acids of AvrPphB was amplified from the pT7$7 / \mathrm{N} \Delta 63$ by using the primers T7RBS and AvrPphB-R. The PCR product was digested with $K p n \mathrm{I} / \mathrm{BamHI}$ and ligated to corresponding sites of pBBR1MCS2. Another deletion derivative of AvrPphB protein lacking amino-terminal amino acid residues 1 to 109 was constructed by PCR amplification. The fragment encoding the carboxyl-terminal 164 amino acids of AvrPphB was amplified from the pBR322/avrPphB by using the forward primer $\Delta 109-\mathrm{F}$ (5' - CGGAGTGGCTTCATATGAGTAGTGACGGAG -3') and the reverse AvrPphB-R (the ATG codon in the forward primer is italicised, NdeI underlined). The PCR product was digested with $N d e \mathrm{I} /$ Bam HI and ligated in corresponding sites of pT7-7. The resulting pT7-7/N $\Delta 109$ plasmid was digested with $N d e \mathrm{I}$ and $\mathrm{BamHI}$ and, after filling the ends with Klenow, ligated to SmaI of pBIN-Hyg-Tx to give $\mathrm{pBIN} / \mathrm{N} \Delta 109$. Next, the truncated coding region of $a v r P p h B$ was amplified from the pT7-7/N $\Delta 63$, using primers T7RBS and AvrPphB-R. The PCR product was digested with $\mathrm{KpnI} /$ BamHI and ligated in corresponding sites of pBBR1MCS2 vector.

\section{Site-directed mutagenesis of AvrPphB.}

To generate the site-directed mutant G63A of AvrPphB, the following steps were followed. Plasmid pT7-7/avrPphB was used to mutagenize the glycine codon at position 63 to an alanine codon, according to the protocol described by Fisher and Pei (1997). The mutagenesis was carried out by PCR amplification using the primers 5'-GATAAAGCATGCGCATCCTCTTCAGGC-3' (forward, mutagenic primer) and $5^{\prime}$-GCCCAGTGTCATTGCCAGGAAT-3' (divergent, nonoverlapping primer). The mutagenic primer contains the mutant codon for alanine (italicised) and an $S p h I$ restriction site (underlined).

Double mutant G63EC64F was obtained by PCR amplification as above, except for using the forward primer 5'-GATAAAGAATTCGCATCCTCTTCAGGC-3'. The mutagenic primer contains two mutant codons, replacing the glycine and cysteine codons at positions 63 and 64 of $a v r P p h B$ with a glutamic acid and phenylalanine codons (italics), respectively, while simultaneously generating an EcoRI restriction site (underlined). Both mutations were confirmed by restriction digestion and sequencing. For expression in Pseudomonas strains and in planta, both mutations were introduced in pBBR1MCS2 and pBIN-HygTx, respectively, by the same procedure described above.

\section{Triparental mating.}

Introduction of the binary plasmid constructs into A. tumefaciens C58C1 (pGV2260) was carried out via triparental mating (Rogers et al. 1988), and transconjugants were selected on Luria-Bertani medium (Sambrook et al. 1989) with $1.5 \%$ bacto-agar, $50 \mu \mathrm{g}$ of rifampicin per $\mathrm{ml}, 100 \mu \mathrm{g}$ of carbenicillin per $\mathrm{ml}$, and $100 \mu \mathrm{g}$ of kanamycin per $\mathrm{ml}$. The broad-host range plasmid constructs were introduced into rifampicin-resistant $P$. syringae pv. phaseolicola race 6 and the $P$. fluorescens strain as above. Transconjugants were selected in KB medium containing the appropriate antibiotics ( $80 \mu \mathrm{g}$ of rifampicin per $\mathrm{ml}, 50$ $\mu \mathrm{g}$ of kanamycin per $\mathrm{ml}, 12 \mu \mathrm{g}$ of tetracycline per $\mathrm{ml}$ ). Both Agrobacterium and Pseudomonas transconjugants were confirmed by PCR analysis.

\section{Plants and pathogenicity tests.}

HR assays or pathogencity tests, or both, were carried out on species N. benthamiana, N. tabacum cv. Xanthi and cv. Wis- consin 38, L. esculentum cv. Rio Grande (near isogenic lines $76 \mathrm{~S}$ and 76R) (all nonhosts to $P$. syringae pv. phaseolicola) and on the French bean Phaseolus vulgaris cvs. TG, A43, Canadian Wonder, and A52. The genotypes of the bean cultivars regarding the presence or absence of the matching $R 3$ gene are given in Table 1. Bean pods were inoculated as previously described (Harper et al. 1987; Hitchin et al. 1989). The compatible interaction on pods is expressed in the form of water-soaked lesions, while incompatibility is in the form of sunken brown lesions (HR) at the sites of injection within 2 days of incubation at $25^{\circ} \mathrm{C}$. Bean primary leaves were inoculated by injection of bacterial suspensions at a concentration of $2 \times 10^{6} \mathrm{CFU} \mathrm{ml}{ }^{-1}$ to $2 \times 10^{8} \mathrm{CFU} \mathrm{ml}^{-1}$ in $10 \mathrm{mM} \mathrm{MgCl}_{2}$ using a needleless syringe and then incubated at $25^{\circ} \mathrm{C}$. Compatible interactions (water-soaking) were recorded after 3 to 4 days and incompatible reactions after $24 \mathrm{~h}$.

\section{Agrobacterium transient expression assay.}

The transient expression of the $a v r P p h B$ gene in N. tabacum cv. Xanthi, N. benthamiana, L. esculentum cv. Rio Grande near isogenic lines 76R and 76S, and Phaseolus vulgaris plants was done according to the method described by Kapila and associates (1997). Briefly, A. tumefaciens strain C58C1 containing the Ti-plasmid pGV2260 (Deblaere et al. 1985) or individual transconjugants were grown in $5 \mathrm{ml}$ yeast extract beef peptone (YEB) medium (Kapila et al. 1997) containing the appropriate antibiotics. Following overnight growth at $28^{\circ} \mathrm{C}$, bacteria were pelleted by centrifugation and resuspended in $5 \mathrm{ml}$ YEB medium containing $10 \mathrm{mM} \mathrm{N}$-morpholino-ethanesulfonic acid (MES) (pH 5.6), antibiotics, and $20 \mu \mathrm{M}$ acetosyringone. The culture was grown overnight to $\log$ phase $\left(\mathrm{OD}_{600}=0.5\right.$ to 0.8$)$ at $28^{\circ} \mathrm{C}$, centrifuged, and resuspended in MMA medium (Murashige-Skoog salts, $10 \mathrm{mM}$ MES, $20 \mathrm{~g}$ of sucrose per 1, $\mathrm{pH} 5.6$, and $200 \mu \mathrm{M}$ acetosyringone) to a final $\mathrm{OD}_{600}$ of 2.4. The Agrobacterium cell suspension was kept at $22^{\circ} \mathrm{C}$ for $1 \mathrm{~h}$. Bacterial suspensions were infiltrated into fully expanded primary leaves of plants using a needleless syringe.

\section{PVX inoculations.}

Four-week-old $N$. benthamiana plants were inoculated with the viral expression vector PVX202, PVX202::avrPphB, or PVX202::N $\Delta 63$ by gently rubbing leaves dusted with carborundum, according to Sablowski and associates (1995). Two leaves of each plant were inoculated with 5 to $10 \mu \mathrm{g}$ Qiagenpurified DNA dissolved in $30 \mu \mathrm{l}$ of $50 \mathrm{mM}$ sodium phosphate buffer, $\mathrm{pH} 7.0$.

\section{$P$ syringae protein extraction and immunoblot analysis.}

Overnight $P$. syringae pv. phaseolicola cultures in $\mathrm{KB}$ with appropriate antibiotics $(1 \mathrm{ml})$ were pelleted, washed with 10 $\mathrm{mM} \mathrm{MgCl}$, and resuspended in $250 \mu \mathrm{l} \mathrm{Laemmli}$ buffer. Samples were boiled for $5 \mathrm{~min}$ at $100^{\circ} \mathrm{C}$, and $20 \mu \mathrm{l}$ were loaded on $14 \%$ sodium dodecyl sulfate-polyacrylamide gels and transferred to nitrocellulose membrane, using standard procedures. Immunoblotting was carried out using antisera raised in rabbits against AvrPphB (Puri et al. 1997) at a 1:5000 dilution. The membranes were developed with a horseradish peroxidase-conjugated anti-rabbit IgG antibody using chemiluminescent substrates (Pierce, Rockford, IL, U.S.A.).

\section{ACKNOWLEDGMENTS}

We thank D. C. Baulcombe for providing the PVX vector, C. Stevens for the plasmid carrying the $\mathrm{N} \Delta 62$ deletion mutant of AvrPphB, and $\mathrm{S}$. Mavrakis for greenhouse assistance. We also thank N. Skandalis for assisting with in planta expression assays. Financial support for this work was provided, in part, by research contracts from the European Commu- 
nity (BIO4-97-2244) and the Secretariat for Research and Technology of Greece (ED313, 98BI-24, and 98BI-34).

\section{LITERATURE CITED}

Anderson, D. M., and Schneewind, O. 1997. A mRNA signal for the type III secretion of Yop proteins by Yersinia enterocolitica. Science 278:1140-1143.

Anderson, D. M., Fouts, D. E., Collmer, A., and Schneewind, O. 1999. Reciprocal secretion of proteins by the bacterial type III machines of plant and animal pathogens suggests universal recognition of mRNA targeting signals. Proc. Natl. Acad. Sci. U.S.A. 96:12839-12843.

Boutin, J. A. 1997. Myristylation. Cell Signaling 9:15-35.

Cornelis, G. R. 2000. Molecular and cell biology aspects of plague. Proc. Natl. Acad. Sci. U.S.A. 97:8778-8783.

Cornelis, G. R., and Van Gijsegem, F. 2000. Assembly and function of type III secretory systems. Ann. Rev. Microbiol. 54:735-774.

Dangl, J. L., Ritter, C., Gibbon, M. J., Mur, L. A., Wood, J. R., Goss, S., Mansfield, J., Taylor, J. D., and Vivian, A. 1992. Functional homologues of the Arabidopsis RPM1 disease resistance gene in bean and pea. Plant Cell 4:1359-1369.

Deblaere, R., Bytebier, B., de Greve, H., Deboeck, F., Schell, J. van Montagu, M., and Leemans, J. 1985. Efficient octopine Ti plasmid derived vectors for Agrobacterium-mediated gene transfer to plants. Nucl. Acids Res. 13:4777-4788.

Fillingham, A. J., Wood, J., Bevan, J. R., Crute, I. R., Mansfield, J. W., Taylor, J. D., and Vivian, A. 1992. Avirulence genes from Pseudomonas syringae pathovars phaseolicola and pisi confer specificity towards both host and nonhost species. Physiol. Mol. Plant Pathol. 40:115.

Fisher, C., and Pei, G. K. 1997. Modification of a PCR-based site-directed mutagenesis method. Biotechniques 23:570-574.

Galan, J. E., and Collmer, A. 1999. Type III secretion machines: Bacterial devices for protein delivery into host cells. Science 284:1322-1328.

Gatz, C., Frohberg, C., and Wendenburg, R. 1992. Stringent repression and homogenous de-repression by tetracycline of a modified CaMV $35 \mathrm{~S}$ promoter in intact transgenic tobacco plants. Plant J. 2:397-404.

Gopalan, S., Bauer, D. W., Alfano, J. R., Loniello, A. O., He, S. H., and Collmer, A. 1996. Expression of the Pseudomonas syringae avirulence protein AvrB in plant cells alleviates its dependence on the hypersensitive response and pathogenicity (Hrp) secretion system in eliciting genotype-specific hypersensitive cell death. Plant Cell 8:1095-1105.

Grant, M. R., Godiard, L., Straube, E., Ashfield, T., Lewald, J., Stattler A., Innes, R. W., and Dangl, J. L. 1995. Structure of the Arabidopsis RPM1 gene encoding dual specificity disease resistance. Science 269:843-846.

Ham, J. H., Bauer, D. W., and Collmer, A. 1998. A cloned Erwinia chrysanthemi Hrp (type III protein secretion) system functions in Escherichia coli to deliver Pseudomonas syringae Avr signals to plant cells and to secrete Avr proteins in culture. Proc. Natl. Acad. Sci. U.S.A. 95:10206-10211.

Harper, S., Zewdie, N., Brown, I. R., and Mansfield, J. W. 1987. Histological, physiological and genetical studies of the responses of leaves and pods of Phaseolus vulgaris to three races of Pseudomonas syringae pv. phaseolicola and Pseudomonas syringae pv. coronafaciens. Physiol. Mol. Plant Pathol. 31:153-172.

Hitchin, F. E., Jenner, C. E., Harper, S., Mansfield, J. W., Barber, C. E., and Daniels, M. J. 1989. Determinant of cultivar specific avirulence cloned from Pseudomonas syringae pv. phaseolicola race 3. Physiol. Mol. Plant Pathol. 34:309-322.

Jenner, C., Hitchin, E., Mansfield, J., Walters, K., Betteridge, P., Teverson, D., and Taylor, J. 1991. Gene-for-gene interactions between Pseudomonas syringae pv. phaseolicola and Phaseolus. Mol. PlantMicrobe Interact. 4:553-562.

Kapila, J., de Rycke, R., van Montagu, M., and Angenon, G. 1997. An Agrobacterium-mediated transient gene expression system for intact leaves. Plant Science 122:101-108.

King, E., Ward, M., and Raney, D. 1954. Two simple media for the demonstration of phycocyanin and fluorescein. J. Lab. Clin. Med. 44:301307.

Kovach, M. E., Elzer, P. H., Hill, D. S., Robertson, G. T., Farris, M. A., Roop, R. M., II, and Peterson, K. M. 1995. Four new derivatives of the broad-host range cloning vector pBBR1MCS, carrying different antibiotic-resistance cassettes. Gene 166:175-176.

Lee, J., Klüsener, B., Tsiamis, G., Stevens, C., Neyt C., Tampakaki, A. P., Panopoulos, N. J., Nöller, J., Weiler, E. W., Cornelis, G. R., Mansfield, J. W., and Nürnberger, T. 2001. HrpZ ${ }_{\mathrm{Psph}}$ from the plant pathogen Pseudomonas syringae pv. phaseolicola binds to lipid bilayers and forms an ion-conducting pore in vitro. Proc. Natl. Acad. Sci. U.S.A. 98:289-294.
Leister, R. T., Ausubel, F. M., and Katagiri, F. 1996. Molecular recognition of pathogen attack occurs inside of plant cells in plant disease resistance specified by the Arabidopsis genes RPS 2 and RPM1. Proc. Natl. Acad. Sci. U.S.A. 93:15497-15502.

Lindgren, P. B., Peet, R. C., and Panopoulos, N. J. 1986. Gene cluster of Pseudomonas syringae pv. phaseolicola controls pathogenicity of bean plants and hypersensitivity on nonhost plants. J. Bacteriol. 168:512-522.

Mansfield, J., Jenner, C., Hockenhull, R., Bennett, M. A., and Stewart, R. 1994. Characterization of avrPphE, a gene for cultivar-specific avirulence from Pseudomonas syringae pv. phaseolicola which is physically linked to $h r p Y$, a new hrp gene identified in the halo-blight bacterium. Mol. Plant-Microbe Interact. 7:726-739.

Miller, J. H. 1972. Experiments in Molecular Genetics. Cold Spring Harbor Laboratory Press, Cold Spring Harbor, NY, U.S.A.

Mudgett, M. B, Chesnokova, O., Dahlbeck, D., Clark, E. T., Rossier, O., Bonas, U., and Staskawicz, B. J. 2000. Molecular signals required for type III secretion and translocation of the Xanthomonas campestris AvrBs2 protein to pepper plants. Proc. Natl. Acad. Sci. U.S.A. 97:13324-13329.

Nimchuk, Z., Marois, E., Kjemtrup, S., Leister, R. T., Katagiri, F., and Dangl, J. L. 2000. Eukaryotic fatty acylation drives plasma membrane targeting and enhances function of several type III effector proteins from Pseudomonas syringae. Cell 101:353-363.

Pirhonen, M. U., Lidell, M. C., Rowley, D. L., Lee, S. W., Jin, S., Liang, Y., Silverstone, S., Keen, N. T., and Hutcheson, S. W. 1996. Phenotypic expression of Pseudomonas syringae avr genes in E. coli is linked to the activities of the hrp-encoded secretion system. Mol. Plant-Microbe Interact. 9:252-260.

Plano, G. V., Day, J. B, and Ferracci, F. 2001. Type III export: New uses for an old pathway. Mol Microbiol. 40:284-293.

Puri, N., Jenner, C., Bennett, M., Stewart, R., Mansfield, J., Lyons, N., and Taylor, J. 1997. Expression of $\operatorname{avrPphB}$, an avirulence gene from Pseudomonas syringae pv. phaseolicola, and the delivery of signals causing the hypersensitive reaction in bean. Mol. Plant-Microbe Interact. 10:247-256.

Resh, M. D. 1994. Myristylation and palmitylation of Src family members: The fats of the matter. Cell 76:411-413.

Resh, M. D. 1999. Fatty acylation of proteins: New insights into membrane targeting of myristoylated and palmitoylated proteins. Biochim. Biophys. Acta 1451:1-16.

Rogers, S. G., Klee, H., Horsch, R. B., and Fraley, R. T. 1988. Use of cointegrating Ti plasmid vectors. Pages 1-12 in: Plant Molecular Biology Manual, section A2. S. B. Gelvin, R. A. Schilperoort, and D. P. S. Verma, eds. Kluwer Academic Publishers, Dordrecht, The Netherlands.

Sablowski, R. W. M., Baulcombe, D. C., and Bevan, M. 1995. Expression of a flower specific Myb protein in leaf cells using a viral vector causes ectopic activation of a target promoter. Proc. Natl. Acad. Sci. U.S.A. 92:6901-6905.

Sambrook, J., Fritsch, E. F., and Maniatis, T. 1989. Molecular cloning. A Laboratory manual, 2nd ed. Cold Spring Harbor Laboratory Press, Cold Spring Harbor, NY, U.S.A.

Shan, L., Thara, V. K., Martin, G. B., Zhou, J. M., and Tang X. 2000. The Pseudomonas AvrPto is differentially recognized by tomato and tobacco and is localized to the plant plasma membrane. Plant Cell 12:2323-2337.

Simonich, M. T., and Innes, R. W. 1995. A disease resistance gene in Arabidopsis with specificity for the avrPph3 gene of Pseudomonas syringae pv. phaseolicola. Mol. Plant-Microbe Interact. 8:637-640.

Sory, M. P., Boland, A., Lambermont, I., Cornelis, G. R. 1995. Identification of the YopE and YopH domains required for secretion and internalization into the cytosol of macrophages, using the $c y a A$ gene fusion approach. Proc. Natl. Acad. Sci. U.S.A. 92:11998-12002.

Stevens, C., Bennett, M. A., Athanassopoulos, E., Tsiamis, G., Taylor, J. D., and Mansfield, J. W. 1998. Sequence variations in alleles of the avirulence gene avrPphE.R2 from Pseudomonas syringae pv. phaseolicola lead to loss of recognition of the AvrPphE protein within bean cells and a gain in cultivar-specific virulence. Mol. Microb. 29:165177.

Tampakaki, A. P., and Panopoulos, N. J. 2000. Elicitation of hypersensitive cell death by extracellularly targeted $\mathrm{HrpZ}_{\mathrm{Psph}}$ produced in planta. Mol. Plant-Microbe Interact. 13:1366-1374.

Taylor, J. D., Teverson, D. M., Allen, D. J., and Pastor-Corrales, M. A. 1996. Identification and origin of races of Pseudomonas syringae pv. phaseolicola from Africa and other bean growing areas. Plant Pathol. 45:469-478.

Teverson, D. 1991. Genetics of pathogenicity and resistance in the haloblight disease of beans in Africa. Ph. D. Thesis, University of Birmingham, UK. 
Towler, D. A., Gordon, J., Adams, S. P., and Glacer, L. 1988. The biology and enzymology of eukaryotic protein acylation. Ann. Rev. Biochem. 57:69-99.

Tsiamis, G., Mansfield, J. W., Hockenhull, R., Jackson, R. W., Sesma, A., Athanassopoulos, E., Bennett, M. A., Stevens, C., Vivian, A., Taylor, J. D., and Murillo, J. 2000. Cultivar-specific avirulence and virulence functions assigned to avrPphF in Pseudomonas syringae pv. phaseolicola, the cause of bean halo-blight disease. EMBO (Eur. Mol. Biol. Organ.) J. 13:3204-3214.

Van den Ackerveken, G., and Bonas, U. 1997. Bacterial avirulence proteins as triggers of plant disease resistance. Trends Microbiol. 5:394398

Van den Ackerveken, G., Marois, E., and Bonas, U. 1996. Recognition of the bacterial avirulence protein AvrBs3 occurs inside the host plant cell. Cell 87:1307-1316.

Van Dijk, K., Fouts, D. E., Rehm, A. H., Hill, A. R., Collmer, A., and Alfano, J. R. 1999. The Avr (effector) proteins HrmA (HopPsyA) and AvrPto are secreted in culture from Pseudomonas syringae pathovars via the Hrp (type III) protein secretion system in a temperature- and pH-sensitive manner. J. Bacteriol. 181:4790-4797.

Vivian, A., Gibbon, M. J., and Murillo, J. 1997. The molecular genetics of specificity determinants in plant pathogenic bacteria. Pages 293-328 in: The Gene-for-Gene Relationship in Host-Parasite Interactions. I. R.
Crute, J. J. Burden, and E. B. Holub, eds. C. A. B. International, Wallingford, UK

Warren, R. F., Merrit, P. M., Holub, E., and Innes, R. W. 1999. Identification of three putative signal transduction genes involved in $R$ genespecified disease resistance in Arabidopsis. Genetics 152:401-412.

Yang, Y., and Gabriel, D. W. 1995. Xanthomonas avirulence/pathogenicity gene family encodes functional plant nuclear targeting signals. Mol. Plant-Microbe Interact. 8:627-631.

Ying-Tsu, L., Zhou, J., and Martin, G. B. 1998. The myristoylation motif of Pto is not required for disease resistance. Mol. Plant-Microbe Interact. 11:572-576.

Zhu, D., Cardenas, M. E., and Heitman, J. 1995. Myristoylation of calcineurin $\mathrm{B}$ is not required for function or interaction with immunophilin-immunosuppresant complexes in yeast Saccharomyces cerevisae. J. Biol. Chem. 270:24831-24838.

Zhu, W., Yang, B., Chittoor, J. M., Johnson, L. B., and White, F. F. 1998 AvrXa10 contains an acidic transcriptional activation domain in the functionally conserved $\mathrm{C}$ terminus. Mol. Plant-Microbe Interact. 11:824-832.

Zhu, W., Yang, B., Willis, N., Johnson, L. B., and White, F. F. 1999. The $\mathrm{C}$ terminus of AvrXa10 can be replaced by the transcriptional activation domain of VP16 from the herpes simplex virus. Plant Cell $11: 1665-1674$. 